Revista Cógnito v.2:1 (2020) 3 - 29

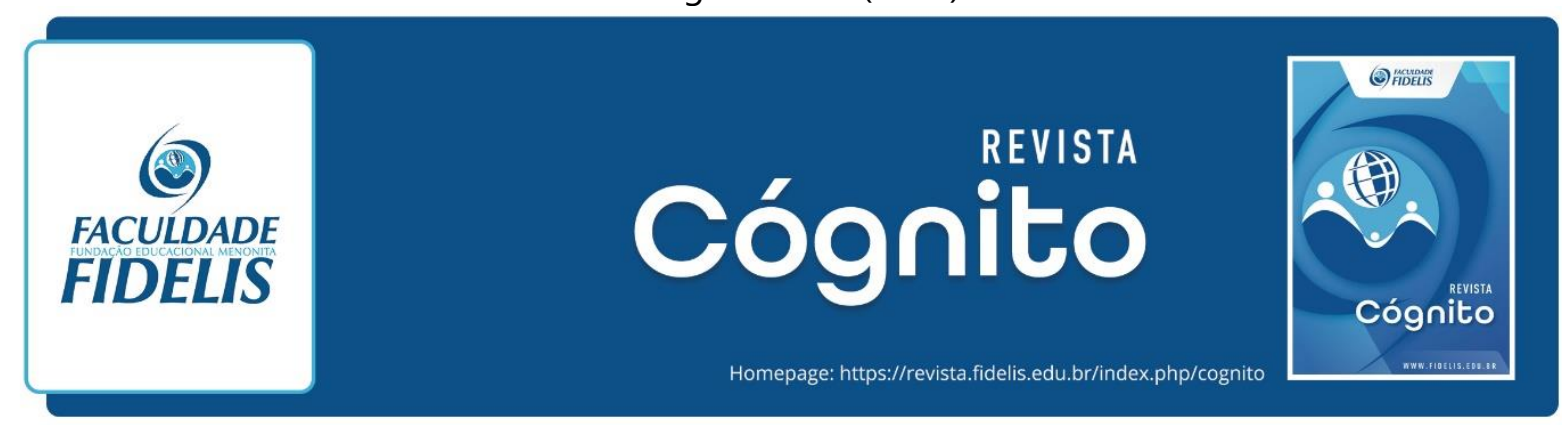

\title{
UMA ANÁLISE FILOSÓFICA, TEOLÓGICA E ANTROPOLÓGICA DO CONCEITO DE COSMOVISÃO
}

\author{
A PHILOSOPHICAL, THEOLOGICAL AND ANTHROPOLOGICAL \\ ANALYSIS OF WORLDVIEW CONCEPT
}

Cristiano Nickel Jr. ${ }^{1}$ Arthur W. Dück ${ }^{2}$

\section{RESUMO}

Qual é o sentido da vida? O que é ser humano? Qual é o sentido da história? Por que as coisas são do jeito que são? Existe vida ou propósito após a morte? Essas perguntas não são respondidas como um questionário de internet ou como uma prova escolar. Elas são respondidas na maneira como vivemos por meio de intenções, reações em determinadas situações e muitas vezes pela boca que fala do que o coração está cheio (Mt 12.34). Para a teologia, cosmovisão é um esquema conceitual pelo qual, conscientemente ou não, aplicamos ou adequamos todas as coisas em que cremos, interpretamos e julgamos como realidade. São os óculos corretos ou incorretos que permitem a capacidade de observar o mundo nitidamente. No entanto, o tema e estudo sobre cosmovisão está confinado a livros de teologia, muitas vezes analisados pelo viés reformado. O fascínio pelo tema leva muitos cristãos a uma intelectualização do evangelho e sua relativização ou promove um ativismo messiânico doentio. Por isso, o objetivo dessa pesquisa bibliográfica é inicialmente buscar uma compreensão e ampliação do conceito de cosmovisão no campo da filosofia, teologia destacando a visão da antropologia missionária de Paul Hiebert que apresenta uma cosmovisão, não apenas como uma estrutura cognitiva, mas afetiva e avaliadora que faz sentido para organizar a vida. $\mathrm{O}$ entendimento amplificado de cosmovisão possibilita uma melhor compreensão e prática integral, apologética e missional do cristão no mundo permitindo assim transformar cosmovisões.

\footnotetext{
${ }^{1}$ Licenciado em música pela Universidade Estadual do Paraná (2014). Especialista em Teologia Aplicada pela Faculdade Fidelis (2017). Aluno do Curso de Bacharelado em Letras Português/Espanhol pela Universidade Estadual de Ponta Grossa (2018). Docente da Faculdade Fidelis - cristiano.nickel@ fidelis.edu.br.

${ }^{2}$ Doutor em Estudos Interculturais - Trinity International University (EUA). Docente da Faculdade Fidelis arthur.duck@fidelis.edu.br.
} 
Palavras-chave: Cosmovisão Cristã. Filosofia. Antropologia. Religião e Cultura. Paul Hiebert.

\begin{abstract}
:
What is the meaning of life? What does it mean to be human? What is the meaning of history? Why are things the way they are? Is there life or purpose beyond death? These questions are not answered by internet quizzes or school exams. They are answered in our daily life through intentions, how we respond in specific situations and many times expressing what overflows from our heart (Matt 12.34). In the theological realm, worldview is a conceptual notion, through which we consciously or not, apply or adapt what we believe in, interpret and judge as real. Worldviews are the glasses that allow us to observe accurately or not the world around us. Worldview studies, however, in the theological literature, are often confined to a Reformed analysis. The fascination for the topic has led many Christians to view the gospel message as mainly intellectual and thus to relativize it, or yet to promote an unhealthy messianic activism. Therefore, the purpose of the bibliographic research is first of all to comprehend and broaden the concept of worldview in the areas of philosophy and theology, stressing the anthropological missionary perspective of Paul Hiebert that presents a worldview, not only as a cognitive structure, but affective and evaluative as well, which is helpful to organize life. This broadened understanding of worldviews allows a better comprehension of the topic and a more holistic, apologetic and missional presence and action in the world, enabling thus to change worldviews.
\end{abstract}

Keywords: Christian worldview. Philosophy. Anthropology. Religion and Culture. Paul Hiebert.

\title{
INTRODUÇÃO
}

Qual é o sentido da vida? O que significa ser humano? Qual é o sentido da história? Por que as coisas deram tão errado? Existe vida ou propósito após a morte? Essas perguntas não são respondidas como um questionário de internet ou como uma prova escolar. Diariamente, respondemos essas perguntas através das nossas ações, intenções, e do que transborda, do que ocupa nosso coração (Mt 12.34 ${ }^{3}$ ). Nem sempre as questões últimas da vida são respondidas de forma cartesiana, pragmática e lógica. Quando comemos, quando conversamos, quando tomamos uma decisão importante, ou quando agimos de má fé, o fazemos com base em determinada cosmovisão. Essas perguntas e outras mais fazem parte de um todo que chamamos de cosmovisão. São pressupostos cognitivos, afetivos e avaliadores pelo qual, conscientemente ou não, aplicamos ou adequamos todas as coisas com base no que cremos, interpretamos e julgamos como verdade, que efetivamente dá sentido à vida real.

\footnotetext{
${ }^{3}$ Todas as referências bíblicas deste texto, quando não especificado, foram extraídos da Bíblia Versão Almeida Revista e Atualizada (ARA).
} 
Cosmovisão, em termos gerais, significa “visão de mundo". São os óculos que usamos para observar a realidade. Esse termo é utilizado com frequência de modo corriqueiro na igreja e na academia. Mas, será que esse conceito está correto? O termo "visão de mundo" é a melhor síntese do conceito? Isso se aplica a todos contextos humanos? Ou, o problema da tradução limita a palavra a conceitos filosóficos e distantes de uma prática efetiva?

O objetivo dessa pesquisa bibliográfica é, inicialmente, buscar uma compreensão mais ampla do conceito de cosmovisão. Faremos essa pesquisa no campo da filosofia e da teologia, destacando a visão da antropologia missionária de Paul Hiebert. O tema é de extrema relevância para que o assunto não se delimite nos campos da razão e do intelectualismo ou na contemplação platônica como a filosofia e a teologia fizeram. Por isso, se faz necessário buscar uma visão mais antropológica para que os cristãos busquem, em sua prática integral e missional, transformar cosmovisões.

No primeiro momento discorreremos sobre como o conceito se desenvolveu no pensamento racionalista de Kant, no idealismo de Fichte e Schelling, na fenomenologia de Hegel e Kierkegaard e na hermenêutica histórica de Dilthey.

Em seguida, veremos no campo da teologia que a apropriação dos filósofos quanto ao termo abriu campo para o neocalvinismo que teve como protagonista James Orr, Abraham Kuyper e Francis Schaeffer e que a partir deste último, diversos autores publicaram obras sobre cosmovisão de um ponto de vista generalizado e indefinido para uma ação cristã efetiva.

Por isso, agregaremos a visão de Paul Hiebert que sintetizou alguns modelos antropológicos para desenvolver uma visão missiológica de transformação de cosmovisões. Veremos que alguns modelos servem como um insight para compreender pequenas sociedades até grandes narrativas que moldam grandes sociedades. Abordaremos os modelos de cosmovisão em categorias diacrônicas e sincrônicas e como se aplica na categoria cristã.

As conclusões dessa pesquisa apresentam uma ampliação do conceito do termo, através da visão antropológica e uma oportunidade de aproximar o assunto que geralmente alimentam as grades curriculares de teologia e não alcançam cristãos leigos. A visão antropológica permite não apenas compreender cosmovisões, mas uma oportunidade missionária de transformá-las.

\section{O CONCEITO DE COSMOVISÃO NA FILOSOFIA}


A definição do termo cosmovisão é complexa. O conceito é apropriado pela filosofia, pela história, pela antropologia, pela linguística e pelo pensamento cristão (HIEBERT, 2016, p. 18). Afirmar que a cosmovisão se restringe à visão de mundo é muito simplista e gera uma série de confusões e ambiguidades. Por isso apresentaremos, de forma introdutória, a construção do conceito pela filosofia, pela teologia e pela antropologia.

$\mathrm{Na}$ filosofia, cosmovisão foi usada pela primeira vez pelo filósofo racionalista ${ }^{4} \mathrm{Kant}$, em sua obra Crítica da faculdade de julgar (GOHEEN, 2016; HIEBERT 2016; NAUGLE, 2017). É a tradução do termo alemão Weltanschauung que significa percepção do mundo ou a capacidade humana de perceber a realidade sensível como uma totalidade ou intuição. Kant acreditava que o ser humano, para chegar a uma Weltanschauung, precisava aplicar-se unicamente à razão e sua autonomia, independente da religião (GOHEEN, 2016; NAUGLE, 2017). Ele empregava o termo para se referir "a uma intuição de mundo no sentido de contemplação do mundo dada aos sentidos” (NAUGLE, 2017, p. 75).

O filósofo idealista Fichte ${ }^{5}$ utilizou o conceito de Weltanschauung como a percepção do mundo sensível e o “princípio de uma 'legislação' superior que harmoniza as tensões entre liberdade moral a causalidade moral [servindo] como uma forma de perceber o mundo empírico" (NAUGLE, 2017, p. 76) A intuição intelectual é possível para superar os limites do conhecimento e alcançar o absoluto. Fichte sugere que Deus é a base para a união dos domínios moral e natural, e que "a unidade real destes é fundamental para a 'cosmovisão' do divino" (NAUGLE, 2017, p. 76). O filósofo conclui que para Deus "nada é natural e nada é sobrenatural, nada é necessário e nada é contingente, nada é possível e nada é real” (NAUGLE, 2017, p. 76). Nesse sentido, a palavra-chave para compreender cosmovisão é a percepção intuitiva e subjetiva da realidade.

\footnotetext{
${ }^{4}$ O Racionalismo foi uma importante corrente filosófica que se desenvolveu a partir de Descartes, da qual a razão puramente natural é o ponto de partida para conhecer a realidade. (MARCONDES, 2008) Essa filosofia adota alguns métodos para conduzir a razão em sua aplicabilidade correta. Kant se apropria dessa corrente e formula o racionalismo crítico e entende que esse projeto "visa dar conta da possibilidade de o homem conhecer o real e de agir livremente [...] O conhecimento resulta da contribuição das faculdades da sensibilidade e do entendimento que constituem o sujeito. (MARCONDES, 2008, p. 311)

${ }^{5}$ O Idealismo alemão foi uma reação ao movimento de rompimento à filosofia de Kant. Marcondes (2008, p. 358) ressalta há duas questões importantes no desenvolvimento do idealismo: “1) a saída sistemática, que se opõe à crítica, dos filósofos que ainda creem na onipotência da razão, como Fichte, levando assim a um ressurgimento da metafísica especulativa, questionada por Kant; e 2) a saída que podemos chamar de 'irracional', adotada pelos românticos e que tem sua inspiração em Schelling". Os idealistas entendem a interpretação da realidade de forma "transcendental como devendo levar à construção de um sistema de saber" (MARCONDES, 2008, p. 358).
} 
Friedrich Schelling entendia que a cosmovisão referia-se aos anseios da humanidade de chegar a um acordo sobre as questões importantes da existência do universo e da natureza, uma compreensão abrangente e coesa do mundo (GOHEEN, 2016, p. 36). O papel do sujeito é ativo como intérprete da realidade, onde não reage à realidade imediatamente. Schelling muda o significado de cosmovisão, afirmando que é "uma maneira autorrealizada, produtiva e inconsciente de apreender e interpretar o universo dos seres" (NAUGLE, 2017, p. 77). Para o filósofo, as cosmovisões são uma resposta para o problema existencial e epistemológico do mundo e permitem esboçar uma resposta para a questão última da existência. Naugle (2017, p. 77-78) conclui que:

\begin{abstract}
Schelling [...] discute duas opções para o intelecto: A inteligência é de dois tipos ou cega e inconsciente, ou livre e com consciência produtiva; a inconsciência produtiva numa cosmovisão, com consciência na criação de um mundo ideal. Assim, Weltanschauung é o produto de um intelecto inconsciente. Ela se refere a impressões subterrâneas sobre o mundo concebidas por uma mente anestesiada, embora funcional. Por outro lado, o intelecto que produz um 'mundo ideal' está plenamente ciente das suas operações e conteúdo. Assim, desde o seu nascimento em Kant até a sua utilização por Schelling, o significado primário do termo mudou de uma percepção sensorial para uma percepção intelectual do cosmo.
\end{abstract}

O conceito de cosmovisão proposto por Schelling e seus antecessores foi recebido positivamente pelos teólogos neocalvinistas como uma resposta indispensável aos embates iluministas ${ }^{6}$ que outrora destronou o cristianismo como verdade pública, colocando-o na esfera de opiniões particulares, valores e crenças individuais (GOHEEN, 2016, p. 150). Esses teólogos propuseram que o cristianismo é uma verdade pública e apresentaram os pressupostos para essa afirmação. Os teólogos neocalvinistas, como James Orr e Abraham Kuyper, utilizaram o conceito para justificar o cristianismo como uma cosmovisão relevante, no entanto reproduziram as narrativas de uma cosmovisão iluminista que enfatizava a racionalidade e a interpretação cognitiva do mundo. Cosmovisão, nesse sentido, está na razão e é uma categoria apenas cognitiva.

\footnotetext{
${ }^{6}$ Segundo Marcondes (2008, p. 296) o "Iluminismo valoriza o conhecimento como instrumento de libertação e progresso da humanidade, levando o homem à sua autonomia e a sociedade à democracia, ou seja, ao fim da opressão" contra toda autoridade que não esteja submetida à razão e à experiência. Nesse caso a fé em Deus foi substituída pela fé no progresso, na razão, na tecnologia e um mundo social racionalmente ordenado (GOHEEN, 2016, 141-50).
} 
No séc. XIX, o uso linguístico do termo foi utilizado por, W. F. Hegel, Søren Kierkegaard, ${ }^{7}$ Wilhelm Dilthey, entre outros autores. Hegel sugere que "as cosmovisões estão incorporadas tanto na consciência individual como na nacional" (NAUGLE, 2017, p. 87-88). Ele afirma que é possível o mundo ter uma cosmovisão particular, assim como é possível um indivíduo desenvolver uma cosmovisão como uma "perspectiva religiosa idiossincrática" (NAUGLE, 2017, p. 88). Para Hegel, cosmovisão está relacionada também com as afeições religiosas e não apenas com o intelecto.

Sobre a questão afetiva, Hegel, na dimensão estética ${ }^{8}$ enfatiza em seus discursos utilizando a palavra Weltanschauung para explicar a visão do artista.

\begin{abstract}
[Hegel] fala do desenvolvimento do fluxo do Espírito manifestado simultaneamente numa Weltanschauung e na arte que a expressa. Ele escreve: 'Esse desenvolvimento é em si mesmo espiritual e universal, visto que a sequência de concepções definidas 'p-de mundo [Weltanschauungen], como a consciência definida, mas abrangente, da natureza, do homem e de Deus, confere a si mesma uma forma artística'. Isso sugere que uma cosmovisão e sua expressão na arte serão diferentes em diferentes épocas históricas [...]. A sequência de diferentes religiões dá origem a uma sequência de diferentes formas de arte. A arte é de fato invocada para representar 'a essência interior do conteúdo' de um dado período (NAUGLE, 2017, p. 89).
\end{abstract}

Rookmaker (2018, p. 172) afirma que o "artista é um profeta [...] [por isso] a arte revela a realidade real, a realidade humana". A arte pode ser uma ferramenta muito útil para interpretar realidades e identificar uma cosmovisão de uma determinada época a arte renascentista de Michelangelo e Botticelli é pautada na realidade, equilíbrio e proporção tal como era a cosmovisão da época. O realismo de Courbet, Manet e Millet revelam a ineficácia de um sistema econômico e as consequências que a Revolução Industrial permeou na realidade social europeia (GOMBRICH, 1999). As vanguardas artísticas de Juan Miró, a musical experimental de Schöenberg e Alban Berg e a desconstrução da pintura em Jackson Pollock revelam muito da cosmovisão do século XX como a descontinuidade, a desconstrução e o derretimento das

\footnotetext{
${ }^{7}$ Vale ressaltar que nessa época filósofos como Hegel, Shopnehauer, Kirkegaard e Nietzsche, refutaram a concepção kantiana de filosofia, abandonando o sentido crítico e interpretando a filosofia transcendental como devendo à construção de um sistema de saber" (MARCONDES, 2008, p. 358).

${ }^{8}$ O pensamento de Hegel e Dilthey é da corrente chamada Romantismo que foi um movimento aparentemente contrário aos ideais do Iluminismo (GOHEEN, 2016. p. 156). Esse movimento filosófico e artístico valorizava as emoções e o sentimento e não uma busca por conhecimentos das causas últimas ou explicação da realidade de forma racional. Nesse período, o estudo da estética artística e da filosofia estética pelos românticos definiu um conceito de que a estética é a protagonista da experiência humana da realidade (MARCONDES, 2008).
} 
grandes narrativas como Estado, família, e outras instituições (BAUMAN, 2001, ROOKMAKER, 2018).

Em síntese, Hegel entende que a "vocação da arte é exibir o espírito da época. As formas de ver o mundo são tecidas na arte e reveladas por ela" (NAUGLE, 2017, p. 90). A arte pode ser uma excelente aliada para compreender cosmovisões e pode muito bem revelar a cosmovisão do artista do meio em que vive (NAUGLE, 2014); ela pode revelar muito da cosmovisão do artista. Isso significa que o entendimento de cosmovisão ultrapassa o campo da racionalidade. Os aspectos de intuição, fruição e afeição são novos adjetivos para o termo.

Søren Kierkegaard utilizava o termo livsanskuelse, tradução da língua dinamarquesa como "visão de vida". Nas obras do autor, o termo aparece mais vezes que a palavra filosofia. Para ele, "a filosofia é um sistema objetivo de pensamento, a cosmovisão é um conjunto de crenças mantidas tão nitidamente por uma pessoa que é apropriado dizer que este vive dentro de sua cosmovisão ou a possui” (GOHEEN, 2016, p. 36-37). É importante destacar que para Kierkegaard, as pessoas só “chegavam a uma 'cosmovisão' por meio de um encontro transformador e existencial com o Cristo vivo" (GOHEEN, 2016, p. 37). O cristianismo não era algo nominal e apenas racional, mas uma experiência autêntica. Essa perspectiva apresenta uma visão introdutória de que o cristianismo é uma cosmovisão que faz sentido para a vida e responde as questões últimas da existência

Para Wilhelm Dilthey, cosmovisão é uma visão de vida tanto abrangente quanto coesa a expressão do significado mais profundo do mundo, que responde às questões fundamentais da vida. A cosmovisão é um complexo de ideias e sentimentos que abrange as crenças e convicções da vida e do mundo, hábitos e tendências emocionais baseados nas mesmas crenças e convicções e um sistema de propósitos que governam a ação e dão um sentido à vida. (GOHEEN, 2016, p. 37). Dilthey entende que a raiz fundacional de qualquer cosmovisão é a própria vida.

O racionalismo de Kant, o idealismo de Fichte e Schelling, a fenomenologia de Hegel e a hermenêutica histórica de Dilthey transformaram o conceito de "cosmovisão" de acordo com sua cosmovisão ou filosofia da época. Como afirma Goheen (2016, p. 38) “o termo cosmovisão traz consigo algumas associações que devem ser afirmadas e outras as quais é preciso ter cautela". A visão de Schelling e Kierkegaard foram aceitas e apropriadas pelo pensamento cristão; outras como a de Kant e Dilthey foram rejeitadas. A visão kantiana, por permitir apenas uma contemplação racional e a de Dilthey, por entender que a história é estática e sem 
possibilidade de mudança (GOHEEN, 2016, p. 38). Podemos acrescentar a visão de Hegel sobre a relação de cosmovisão e arte como uma forma de ver e interpretar o mundo.

\section{CONCEITO DE COSMOVISÃO NA TEOLOGIA}

James Orr foi o primeiro pensador cristão a usar o conceito de cosmovisão. A cosmovisão deveria ser cristocêntrica como o cumprimento da história da salvação e que está implícita na narrativa bíblica em sua totalidade, onde os cristãos precisam expressar essa cosmovisão claramente (GOHEEN, 2016, p. 40). Para Naugle (2017, p. 20), “a fé cristã fornecia esse ponto de vista e desenvolvia sua visão de vida e seu princípio mais sublime num 'todo ordenado' [..] na sua totalidade, como um sistema".

No percurso dos teólogos, destacamos Abraham Kuyper, que viveu a cosmovisão cristã de forma multifacetada - como jornalista, teólogo, primeiro-ministro da Holanda, e fundador da Universidade Livre de Amsterdã — considerado como um dos fundadores do neocalvinismo holandês (GOHEEN, 2016). O neocalvinismo defende, em primeiro lugar, que a redenção de Deus em Cristo e por meio dela restaura toda a criação; em segundo lugar, Deus é soberano e pela sua lei e palavra ordena toda a realidade; por último, Deus decretou o mandato cultural (Gn 1.26-28), onde a humanidade exerce mordomia ao desenvolver, para a glória de Deus, a cultura ao longo da história (GOHEEN, 2016, p. 42). Kuyper entendia que o calvinismo era a forma de promover um cristianismo revitalizado que pressupunha a presença cristã renovada em todas as esferas da vida. Ele observava, p.e., que a modernidade é uma cosmovisão contrária à tradição cristã, como um combate, uma luta que somente através de uma visão abrangente da narrativa bíblica seria possível resistir ao adversário (GOHEEN, 2016, p. 40).

Outro pensador e teólogo que deu continuidade à visão de Abraham Kuyper foi Francis Shaeffer. Ele entendia que a cosmovisão cristã era mais do que um caminho para a salvação pessoal e para vida eclesiástica, era uma nova interpretação da realidade. Como apologista e evangelista, a preocupação do teólogo era quanto à cultura moderna e seu relativismo. Para ele, o secularismo devorou a graça e se enraizou em todos os aspectos da vida social, cultural e política. Naugle (2017, p. 46) comenta que, para Schaeffer, o cristianismo "não é simplesmente uma religião que diz aos seres humanos como eles podem ser perdoados. É uma visão de mundo e de vida total. Os cristãos precisam reconhecer que sua fé tem coisas importantes a dizer sobre a vida humana como um todo". 
Francis Schaeffer inspirou diversos estudantes contemporâneos para o estudo e desenvolvimento da cosmovisão cristã: Albert Wolters, John Stott, Brian Walsh, Richard Middleton, James Sire, Arthur Holmes, N.T. Wright, Charles Colson e Nancy Pearcey (GOHEEN, 2016).

Nancy Pearcey propõe uma cosmovisão cristã como o resgate do cristianismo do seu cativeiro cultural, argumentando que não se trata apenas de uma verdade religiosa, mas de uma verdade ontológica, uma verdade pública. É a verdade absoluta de Deus que se insere em todos os aspectos da vida humana, inclusive intelectual. Pearcey defende que o passo fundamental para formar uma cosmovisão cristã é superar o dualismo coração/cérebro (PEARCEY, 2006).

Outro teólogo que possui diversos escritos sobre cosmovisão é James Sire. ${ }^{9}$ Para ele, cosmovisão é um conjunto de pressuposições que de maneira consciente ou não, sustentam o homem no mundo em que vive (GOHEEN, 2016, p. 44). Olhamos através de lentes e raramente olhamos para nossos próprios óculos. Sire compreende a cosmovisão como um compromisso que envolve a mente e a alma, onde o centro de operação está situado no "eu", que procedem os pensamentos e ações pessoais. Cosmovisão é expressa em uma história ou conjunto de pressupostos, em que as suposições que podem ser verdadeiras, de forma consciente ou não, são fundamentos sobre o qual vivemos (SIRE, 2018). O autor entende que há sete cosmovisões que competem pela supremacia e proeminência no pensamento ocidental:

a) Teísmo cristão - crença em Deus como realidade última;

b) Deísmo - teísmo sem o atributo da pessoalidade de Deus;

c) Naturalismo - teocentrismo para o antropocentrismo; confiança na razão humana;

d) Niilismo - confiança antropocêntrica corroída;

e) Existencialismo - tenta superar o niilismo, afirmando o poder do indivíduo de concretizar, pela sua vontade, sua própria concepção de realidade;

f) Monismo panteísta oriental - síntese do pensamento Nova Era com o existencialismo;

g) Pós-modernismo - apreensão da realidade e verdade como fenômeno linguístico (SIRE, 2018).

\footnotetext{
${ }^{9}$ Algumas obras do autor que abordam o tema com propriedade como a obra "Dando nome ao elefante: cosmovisão como um conceito” (São Paulo, Monergismo, 2012) e Universo ao lado (São Paulo, Monergismo, 2018).
} 
É um equívoco, porém, pensar que a cosmovisão cristã é de propriedade exclusiva do protestantismo. No catolicismo também há um padrão de pensamento e uma visão de mundo. A cosmovisão católica, mesmo que apareça poucas vezes em sua literatura, ainda assim permeia a vida e o pensamento de seus adeptos. Um dos expoentes no assunto foi João Paulo II, p.e., considerado um papa "cosmovisionado" [sic] (NAUGLE, 2017, p. 49). A teologia católica romana propõe uma visão realista de mundo (cosmovisão) buscando mediar as tensões existentes entre a estrutura criacional e a trágica realidade do pecado e suas consequências. João Paulo II se baseava em três convicções fundamentais. A primeira é que os seres humanos possuem características universais como a busca pela verdade e o desejo de descobrir as respostas últimas da vida. A segunda convicção é de que o ser humano é comprometido com filosofias e religiões particulares. É o produto daquilo que pensa e adora, é um produto do culto, definição esta de cultura (NAUGLE, 2017, p. 49). A última convicção é que tendo em vista que a cultura modela a história, o impulso religioso, "para alterar a experiência humana para melhor, uma transformação radical deve ocorrer no nível cultural e nos conjuntos de ideias básicas que o compõem" (NAUGLE, 2017, p. 49). Para o papa, "o mistério do Cristo encarnado é a pedra angular da cosmovisão humanística, cujas implicações abraçam a totalidade da vida (NAUGLE, 2017, 49-50).

O conceito de cosmovisão na teologia é um assunto que pode despertar interesse metafísico e epistemológico permitindo levantar algumas críticas e possíveis objeções: como a intelectualização do evangelho, relativização do cristianismo, desconexão das Escrituras, messianismo doentio, ou ainda retroalimentar o cristianismo de classe média, negligenciando os pobres e marginalizados (GOHEEN, 2016, p. 47-52). Diversos autores citados anteriormente possuem uma cosmovisão ocidental moderna e se preocupam com o mundo ocidental. Sobre o assunto, Hiebert (2016, p. 171) escreve:

Eles creem em Deus e na história cósmica da criação, queda e redenção, juízo final e nova criação. Isso lhes dá significado e propósitos supremos na vida. No entanto, vivem em um mundo comum, o qual explicam em termos naturalistas — e nele há pouco espaço para Deus.

Hiebert denuncia o problema da contemplação platônica do conhecimento. Cosmovisão pode ser tornar um tema fascinante, delineado e intrínseco, podendo levar a apenas uma intelectualização do tema sem fins práticos para a vida cristã. Categorizar o mundo ocidental em possíveis sete cosmovisões, como James W. Sire (2018) faz é colocar todas as culturas em 
um recipiente padronizado. $\mathrm{E}$ as sociedades tradicionais? $\mathrm{E}$ as sociedades rurais? De que forma categorizar os aborígenes da Austrália? Ou os índios caiapós do Brasil? De que forma categorizamos sociedades do interior do Amapá ou de Santa Catarina?

Até agora percebemos que os conceitos de cosmovisão apresentam uma abrangência genérica, de cunho epistemológico e metafísico que levam a algumas críticas e objeções, vistas anteriormente. É importante analisar a apropriação do conceito de cosmovisão pela antropologia. Isso possibilita, de forma embrionária, responder às questões elencadas no parágrafo anterior.

\section{O CONCEITO DE COSMOVISÃO E SUA ABORDAGEM NA ANTROPOLOGIA}

A obra de Paul Hiebert, Transformando cosmovisões: uma análise de como as pessoas mudam (Vida Nova, 2016) apresenta uma abordagem do ponto de vista da antropologia missionária que possibilita uma visão aplicada e prática do estudo de cosmovisão. Infelizmente nenhum dos teólogos citados anteriormente apresentaram em seus estudos referência alguma às obras de Hiebert.

De acordo com a breve biografia citada no livro acima, Paul Hiebert (1932-2007) foi professor de Missão e Antropologia na Trinity Evangelical School. Serviu como pastor e missionário na Índia. A experiência missionária no Oriente possibilitou desenvolver uma cosmovisão antropológica que pudesse dialogar e entender as cosmovisões em contextos humanos: quais os métodos de sua análise, de que forma funcionam as cosmovisões de sociedades orais (animistas) sem deixar de apresentar um estudo e compreensão holística da cosmovisão moderna e seus desdobramentos (HIEBERT, 2016).

Em antropologia, a ideia de cosmovisão foi iniciada nos estudos conceituais de cultura. Inicialmente, diversos antropólogos classificaram as sociedades humanas em categorias minimizadoras e preconceituosas em relação à civilização ocidental. Tais conceitos foram rejeitados por Franz Boas onde propôs a mudança de foco do conceito — "cultura é como um conjunto de crenças e práticas que fazem sentido a um determinado povo" (HIEBERT, 2016, p. 20). A partir da preocupação em compreender o funcionamento das culturas humanas, diversos antropólogos desenvolveram teorias e métodos para analisá-las. Analisaremos alguns autores que Paul Hiebert utilizou para desenvolver sua antropologia missionária. 
Mary Douglas desenvolveu o estudo de culturas com base no antagonismo entre sujeira e limpeza. Algumas sociedades, como a Índia, baseiam-se em conceitos de pureza vs. poluição. Pecar não significa quebra de leis impessoais ou de relacionamentos; pecar é profanar. (HIEBERT, 2016, p. 22). A Pandemia do COVID-19 pode ser um exemplo clássico para compreender o estudo por Mary Douglas. Estar em aglomerações, não possuir hábito de higienizar as mãos, não manter a distância na fila do supermercado ou do banco, ou não usar máscara se tornou algo na categoria de sujeira e fora do sistema de classificação cultural no presente momento, o ano 2020. Paradoxalmente, isolamento social, não conversar pessoalmente com os outros, ou não ir à igreja nos cultos de domingo, tornou-se algo na categoria de pureza. Douglas estudou também as ações individuais e culturais em grades (liberdade e restrição moral) e grupos (realização conjunta ou autônoma) (DOUGLAS, 1976; HIEBERT, 2016, p. 22).

Figura 1 - Grupos e grades de Mary Douglas

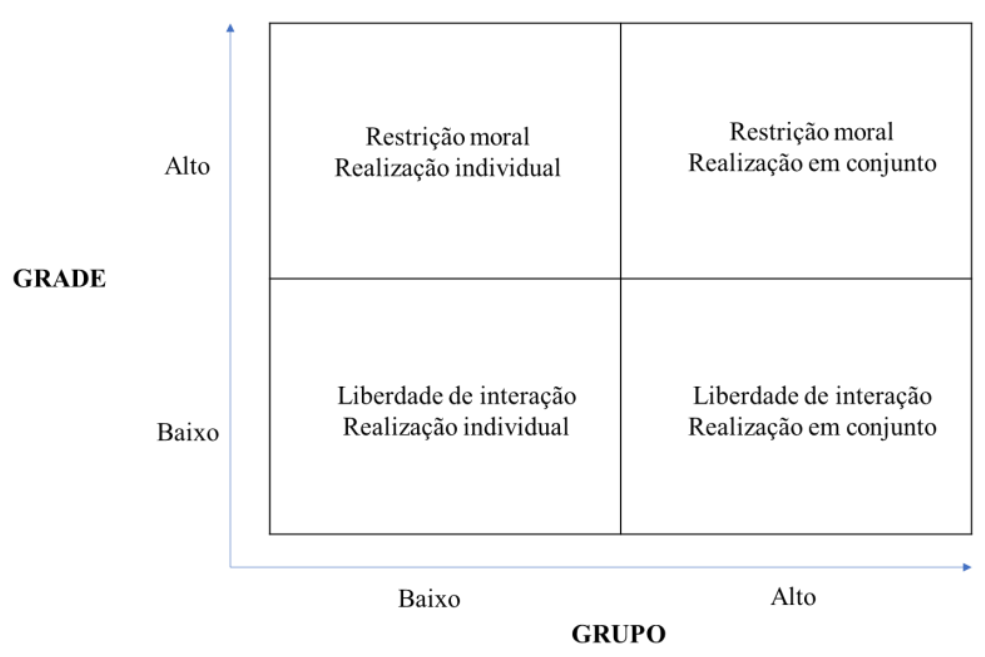

Fonte: Elaboração própria com base em DOUGLAS, 1976 e HIEBERT, 2016, p. 22

Pessoas que têm grade baixa têm facilidade e liberdade de interagir com outras. Culturas que possuem grade alta permitem a coação por normas culturais rígidas e definidas, que precisam ser obedecidas. O grupo baixo define autonomia do indivíduo; o grupo alto, a realização de coisas juntas. A compreensão dos dois eixos auxilia o entendimento dos tipos de situações, de indivíduos e culturas. Abaixo, exemplificaremos esse estudo dos eixos ilustrados na Figura 1 (HIEBERT, 2016, p. 22)

a) Grade baixa, grupo baixo: a cultura norte-americana e europeia defende a autonomia das pessoas e permite uma liberdade de expressão. Múltiplas configurações familiares, opção 
por gênero sexual, afrouxamento das questões éticas como eutanásia, aborto, etc. (HIEBERT, 2016, p. 22).

b) Grade alta, grupo baixo: a cultura budista nos países orientais é definida por códigos de conduta rígida e defende que o indivíduo viva o ascetismo passando pela dor e pelo sofrimento dedicando-se à meditação e a busca do ideário espiritual individual (AZEVEDO, 2002, p. 69).

c) Grade alta, grupo alto: A sociedade indiana de maneira geral vive em grandes comunidades e um rígido sistema de restrição moral (HIEBERT, 2016, p. 374). Outro exemplo são as comunidades menonitas de maneira geral (SIEMENS, 2010, p. 35).

d) Grade baixa, grupo alto: sociedades alternativas de cosmovisão animista. Algumas práticas religiosas afro-brasileiras como o catimbó permitem uma liberdade de conduta e exaltam a vivência em comunidade de forma livre (AZEVEDO, 2002, p. 90). Comunidades de política anarquista entram nessa categoria.

Edward Sapir e Benjamin Whorf, estudaram a estrutura linguística das culturas e desenvolveram a teoria estruturalista Sapir-Whorf, em que a língua falada configura o que pensamos e é definidora da realidade (HIEBERT, 2016, p. 22). Há muitas formas diferentes de pensar e observar o mundo, cada um com sua língua particular que permite a maneira de compreender a realidade. Em síntese, a hipótese Sapir-Whorf aponta que as pessoas que falam línguas diferentes, veem o mundo diferente e que pelos modelos linguísticos conhecemos os modelos socioculturais (MARTELOTTA, 2012, p. 126). Sobre isso, González (2011, p. 41) complementa:

[...] como parte desse elemento interno de uma cultura, o idioma, que nos serve para nos comunicar uns com os outros, é reflexo desta cultura e, ao mesmo tempo, dá-lhe forma. É por isso, que certo modo, a reflexão acerca da língua pode nos levar também a reflexões sobre cultura. [...] o que as culturas fazem não é apenas fornecer os meios pelos quais um grupo responde ao seu ambiente, mas também o modo como o interpreta. Essa interpretação começa com o idioma, mas vai muito além disso, chegando até o mito e a religião.

Não adentraremos no campo linguístico, mas precisamos entender que pela língua podemos conhecer uma cosmovisão ao mesmo tempo que podemos analisar cosmovisões de forma equivocada, nos confundindo com os códigos e signos linguísticos de nossa própria língua como forma interpretativa do outro. 
Bronislaw Malinowski se interessou pelo estudo dos nativos e como eles entendiam e respondiam sobre a realidade das coisas, concluindo que cada cultura dá os seus membros uma visão normativa sobre o mundo e sobre a vida. Ele desenvolveu uma teoria chamada de funcionalismo que permite explicar as relações sociais e produtos culturais dos indivíduos deduzindo que estas relações determinam a sociedade e como ela funciona (MALINOWSKI, 2015, p. 41).

Robert Redfield buscou compreender cada cultura quanto às questões últimas do universo exterior, definindo o conceito de cosmovisão como a imagem que os membros de um povo ou cultura têm das propriedades exteriores e de como o homem vê a si mesmo em relação aos outros - perguntas como “onde estou?”, “entre o que eu caminho?”, “qual é a minha relação com essas coisas?" são perguntas que definem a cosmovisão característica de cada cultura (HIEBERT, 2016, p. 23). Redfield delimitou o estudo sobre as dimensões cognitivas de cultura, compreendendo que, "embora os seres humanos vejam o mundo de forma diferente uns dos outros, todos vivem no mesmo mundo e todos devem lidar com certos elementos universais da cosmovisão" (HIEBERT, 2016, p. 23).

Michael Kearney desenvolveu o conceito de cosmovisão na perspectiva marxista. Cosmovisão é uma maneira de olhar a realidade externa, em que a pessoa deve adquirir uma compressão de si mesma e de quem ela é no mundo. Essa realidade precisa ser classificada em taxonomias para que as pessoas procurem explicar a causalidade (causa e efeito) das experiências baseadas na observação da natureza e no uso do senso comum (HIEBERT, 2016, p. 24). A cosmovisão, segundo Kearney, se dá na compreensão de espaço e tempo. O espaço é compreendido não apenas no âmbito geográfico, mas sagrado, moral e pessoal e conceitos de outros mundos, céus e infernos; o tempo é compreendido com base nas relações entre uns e outros no tempo histórico. Para Hiebert (2016, p. 25), os modelos de Kearney e de Redfield são estáticos. Não há muito espaço para mudanças e conflitos tampouco é possível avaliar sistemas culturais como bom e mal.

Para Morris Opler, as culturas podem compartilhar semelhanças de cosmovisão, mas cada uma é singular em determinada temática. Morris propõe o embate tema-contratema. Os temas de cosmovisão geralmente controlam o comportamento e estimulam a uma ação, que pode ser aprovada ou disseminada em uma sociedade. Os contratemas são fatores de equilíbrio para que os temas não se tornem poderosos e destruam as culturas (HIEBERT, 2016, p. 25). P.e., o individualismo ocidental (tema) ao extremo direciona à solidão e ao isolacionismo e como contratema, a família, a escola, a igreja amenizam os efeitos do individualismo. 
(HIEBERT, 2016, p. 26). Hiebert se interessa pela visão tema-contratema proposto por Opler, por não ser um modelo de observação de culturas, mas que permite a possibilidade de transformação de culturas e de desenvolver ponte com o evangelho. O modelo de Opler também possibilita ver, em uma cultura, os efeitos do pecado e do mal nas cosmovisões (HIEBERT, 2016, p. 27 e 28)

Walter J. Ong, questiona a perspectiva moderna de cosmovisão, pois a ênfase à visão é proeminente sobre o som. Para Ong, os sons, em determinadas culturas, são considerados mais importantes do que a visão (HIEBERT, 2016, p. 29). As palavras faladas são poderosas - os sons corretos podem fazer chover, levar o inimigo ao fracasso, p.e; determinadas orações e rezas possibilitam uma benção; sons de tambores e gritos, protegem as pessoas dos maus espíritos ou levam ao estado de transe. "Portanto não é de se admirar que os sons levem as pessoas a crer em espíritos [...] a visão, ao contrário, tem raro senso de mistério e deixa pouco espaço para o que não é visto (HIEBERT, 2016, p. 29).

Para Stephen Pepper, as cosmovisões se baseiam em metáforas orgânicas e metáforas mecânicas. “[...] metáfora orgânica [...] vê o mundo e a realidade como realidade suprema como seres vivos [...] a metáfora mecânica [...] trata o mundo como máquina impessoal, um relógio, dirigida por forças invisíveis que atuam de acordo com leis físicas” (HIEBERT, 2016, p. 29).

Clifford Geertz entende cosmovisão como a representação feita por um povo das coisas como são em sua realidade externa como ideias abrangentes. Geertz propõe que a crença religiosa e o ritual se confrontam e se confirmam mutuamente e que a natureza do bem e do mal é arraigada na própria realidade (GEERTZ, 2015, p. 175). Ele diferencia cosmovisão de ethos. Cosmovisão são os pressupostos cognitivos; ethos corresponde aos pressupostos avaliativos e afetivos. Tais distinções são, na verdade, essencialmente correlacionados e se completam, conferindo significado um ao outro (HIEBERT, 2016, p. 30).

Finalizando as breves análises sobre cosmovisão antropológica, Talcott Parsons, Edward Shils e Clyde Kluckhohn desenvolveram uma abordagem sistêmica para o estudo antropológico. Os seres humanos possuem três dimensões - cognitiva, afetiva e moral. Essas dimensões atuam simultaneamente nas experiências humanas. As pessoas pensam a respeito das coisas, possuem sentimento em relação a elas e avaliam entre o certo e errado com base na cognição e na afetividade (HIEBERT, 2016, p. 31). Com base nos autores acima, Hiebert construiu um conceito sintético de cosmovisão: 
[Cosmovisão] são pressuposições e estruturas cognitivas, afetivas e avaliativas fundamentais que um grupo adota em relação à natureza da realidade e que utiliza para organizar sua vida. Ela envolve as imagens ou mapas mentais que as pessoas fazem da realidade de todas as coisas que os seres humanos empregam para viver sua vida. É o cosmo considerado verdadeiro, desejável e moral para uma comunidade. (HIEBERT, 2016, p. 31)

A obra de Paul Hiebert, Transformando cosmovisões (2016), possui uma vasta pesquisa apresentando métodos, funções e análise de cosmovisões. Ele se apropria da filosofia, da teologia, da linguística, da sociologia, da etnografia entre outras ciências. Nesta pesquisa, daremos destaque a um dos métodos que ele utiliza para comparar cosmovisões: utilizando as a teoria dos conjuntos.

\section{COSMOVISÃO E ESTRUTURA SINCRÔNICAS}

Hiebert seleciona alguns modelos para desenvolver estudos de cosmovisão. O modelo de tema-contratema de Opler; as ideias de Parsons, Shils e Kluckhohn para tratar das três dimensões da cosmovisão antropológica - cognitiva, afetiva e avaliativa; e para uma elaboração teórica, as sete categorias de Redfield como temas sugestivos para investigar uma cultura, embora Hiebert não tenha apresentado em sua obra quais estas categorias (HIEBERT, 2016, p. 31).

Os modelos de cosmovisão podem ser categorizados em diacrônico e sincrônico. Como exemplo figurado, a estrutura sincrônica é microscópica: utilizamos recursos para ampliar o entendimento de uma determinada cosmovisão. Para realizar essa ampliação é necessário recorrer aos recursos da antropologia missionária e demais ciências como a sociologia e a psicologia, as estruturas sincrônicas das cosmovisões operam no que chamamos de "metáforasraiz" para estruturação de realidade e entendimento de como ela opera (HIEBERT, p. 75 e 78).

As categorias diacrônicas, por sua vez, são telescópicas — é necessário reduzir a narrativa ou história para compreender a cosmovisão de forma cósmica ou global. Hiebert alerta sobre o perigo de examinar a estrutura fundamental das cosmovisões utilizando somente recursos diacrônicos. Um dos perigos é o idealismo platônico em que a realidade absoluta é estática e que a mudança é uma questão de aparência. As estruturas humanas são estruturas orgânicas e dinâmicas e em constante mudança, onde as análises são tentativas de aproximação de resultados (HIEBERT, 2016, p. 37). 
Não é possível estudar uma cosmovisão de forma exaustiva em busca de uma completude. Sabemos que ao observar pelo telescópio uma estrutura como, p.e., a Terra, podemos verificar uma imensa parte coberta de água e conseguimos localizar os continentes. Mas se apenas ficarmos na contemplação diacrônica, seremos muito superficiais e indiferentes ao que de fato ocorre dentro do planeta. Exemplificando, a poluição, as epidemias, ou problemas ambientais não se solucionam utilizando o telescópio, ou observando de fora, pela contemplação estática. É preciso interferir e agir no ambiente. Por isso as estruturas sincrônicas da antropologia missionária e demais ciências humanas podem auxiliar em uma ação micro elas nos ajudam a compreender os pormenores de uma comunidade de pequenas sociedades.

Dentro das estruturas sincrônicas, Hiebert (2016) trabalha com as temáticas: profundidade, formação de categorias, signos, causalidade, tema e contratemas, pressupostos epistemológicos, temas cognitivos e temas afetivos. Neste artigo desenvolveremos apenas a proposta de categorização de cosmovisões, e como exemplo, mostraremos como elas influenciam nas práticas cristãs.

\subsection{Categorias de conjuntos: intrínsecos/extrínsecos delineados/indefinidos}

Somos, por natureza, induzidos a categorizar as coisas: feio e belo; sujo e limpo; organizado e desorganizado, convertido e não-convertido; bom e mau; rico e pobre etc. No entanto, o modo como categorizamos as coisas influenciam a compreensão do que temos dela. Por exemplo, o que significa ser cristão? Muitas respostas e categorias são formadas para responder essa pergunta. Alguns dirão que para ser cristão é necessário realizar sacramentos ou ordenanças, passar pelos catecúmenos ou fazer um curso de integração. Outros responderão que a mudança de comportamento é o que define um cristão. Muitos afirmarão que a evidência de ser cristão é a mudança de crença e afirmação das ordenanças e dogmas de determinada tradição eclesiástica (HIEBERT, 1994, p. 22).

Na proposta de conjuntos, Hiebert observa duas variáveis importantes para definir uma cultura: a primeira está ligada ao fundamento sobre o qual os elementos são designados como parte de uma categoria - conjuntos intrínsecos e extrínsecos; a segunda variável são as categorias ligadas com os seus limites ou fronteiras - conjuntos delineados e indefinidos. (HIEBERT, 1994, p. 22).

Conjuntos formados com base na natureza essencial dos próprios membros — naquilo que são na sua essência, p.e., maçãs são objetos comestíveis, redondas, e é uma fruta, no 
entanto, não pode ser uma ameixa ou banana; a maioria dos substantivos na língua portuguesa corresponde aos conjuntos intrínsecos.

Conjuntos extrínsecos são formados no relacionamento com outros objetos ou com um ponto de referência e não sobre o fundamento de que os objetos são. P.e., somos dois irmãos porque somos filhos de um pai e de uma mãe. Se somos filhos dos mesmos pais, somos irmãos, não por causa do conjunto intrínseco, mas por causa do relacionamento com um ponto de referência em comum — os pais (HIEBERT, 1994, p. 22).

Conjuntos delineados são conjuntos que têm limite rigidamente definidos — os objetos pertencem ou não ao grupo. Conjuntos indefinidos não têm limites bem definidos - as categorias fluem de um lado para outro. P.e., o dia se torna noite, e uma montanha se torna uma planície sem uma transição clara (HIEBERT, 1994, p. 22).

Combinando as características acima, temos quatro categorias que refletem e criam uma certa visão da realidade, uma cosmovisão distinta. É importante conhecer essas categorias de cosmovisão e como elas influenciam nossa vivência de acordo com as escrituras. Questionamentos sobre a essência do cristianismo, o entendimento e a compreensão das religiões são influenciados por categorias existentes entre diversas culturas (HIEBERT, 1994, p. 22).

Figura 2 - Teoria dos conjuntos

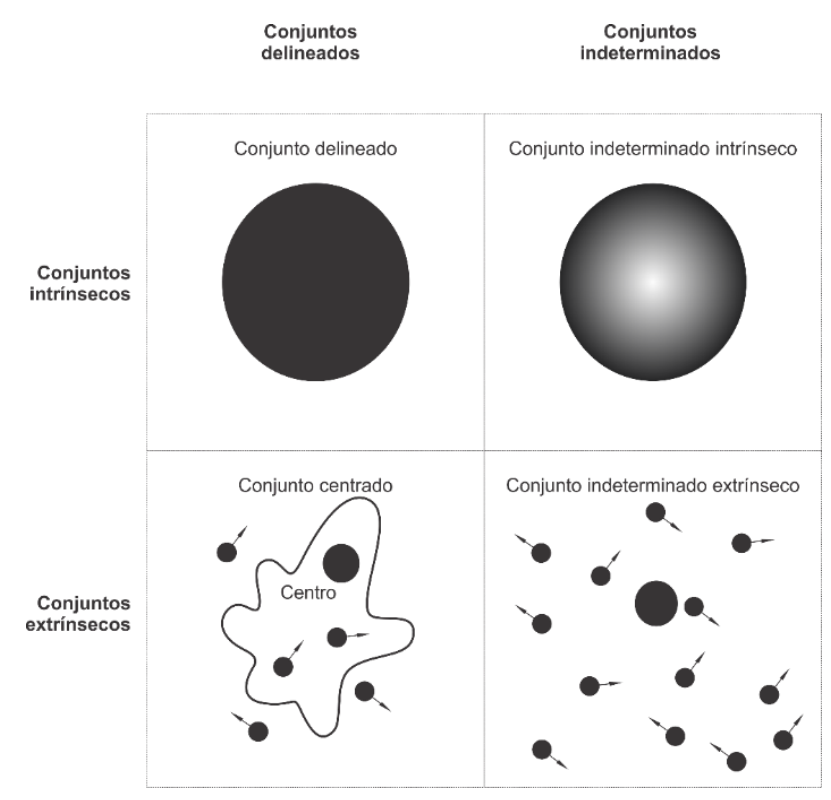

Fonte: adaptado de Hiebert (2016, p. 46) 


\subsubsection{Conjunto delineado}

As principais características dos conjuntos delineados são as definições estruturais, criada quando são alistadas as características essenciais para pertencer ao grupo. É definida por uma divisão clara onde há um grande esforço em manter a definição e divisão. A questão central desse conjunto é se o objeto está dentro ou fora de uma determinada categoria, onde não há variação possível dentro da estrutura da categoria (HIEBERT, 2016). Conjuntos delineados são estáticos, onde a única mudança possível é do exterior para o interior do conjunto. Esses conjuntos são muito utilizados no mundo ocidental por serem considerados ontológicos quanto às estruturas últimas, universais e imutáveis (HIEBERT, 1994, 2016). Conjuntos delineados são fundamentais para a compreensão da ordem e uniformidades. P.e. tirar as ervas daninhas do quintal, cores uniformes das paredes, os talheres separados na gaveta, a música tonal, regras de trânsito, limpeza etc. Essa categoria, disseminada no mundo ocidental, é uma herança grega - quando os filósofos falavam sobre a natureza intrínseca e da realidade em termos de categorias claramente delimitadas (HIEBERT, 1994, p. 24,25)

\subsubsection{Prática cristã e igreja como conjunto delineado}

O que acontece quando o nosso conceito de cristão é definido em temos de conjunto delineado? No conjunto delineado classificamos se a pessoa é cristã ou não baseado naquilo que ela é, julgando e olhando para as características externas que podemos ouvir ou ver. Há teste de ortodoxia - afirmação verbal de uma crença em doutrinas específicas; e o teste de ortopraxia - comportamento correto (HIEBERT, 1994). Procura-se evidências de fé na vida transformada das pessoas. O dualismo cristão e não cristão é um grande esforço para não secularizar o conjunto. A pergunta central é se a pessoa está dentro ou fora do círculo de fé; todos enxergam os de dentro do conjunto como cristãos, não importando o grau de maturidade. A conversão é enfatizada como mudança essencial e dramática onde todos têm de experimentar. Muitas vezes a santificação não é prioritária, ficando em segundo plano (HIEBERT, 1994, p. 26-27).

A igreja é um agrupamento de pessoas, uniforme e homogêneo, em que todos concordam com as mesmas doutrinas e observam os mesmos comportamentos, onde há grande exigência para a membresia. As igrejas se comportam como clubes ou associações voluntárias, que satisfazem necessidades pessoas específicas, o evangelismo é a maior tarefa da igreja, 
trazendo as pessoas para a categoria. Conversão é o ápice para entrar na estrutura, discipulado e maturidade são secundários (HIEBERT, 1994, p. 27 e 28)

Quanto as missões, o objetivo de ganhar as pessoas para Cristo é colocá-las num processo sistemático (discipulado, catequese, integração) para então batizá-las. Igrejas plantadas por estruturas delineadas copiam as mesmas doutrinas e regras da "igreja-mãe". O treinamento de líderes é ineficaz, uma vez que é um processo longo capacitá-los para se conformar à estrutura. Não há espaço para o sincretismo, pois é prejudicial para o cristianismo, a questão apologética é alta (HIEBERT, 1994, p. 29).

\subsubsection{Conjunto indefinido intrínseco}

Exemplos de categorias indefinidas e intrínsecas é como o dia e a noite, o envelhecimento, uma montanha que passa por processo de erosão, o vermelho por se tornar violeta ou alaranjado etc. São conjuntos matemáticos que não têm margens claras e há graus de inclusão na estrutura, ou seja, a membresia de um grupo depende da situação intrínseca do membro, naquilo que é. As fronteiras são indefinidas, com degraus de inclusão dentro do conjunto (HIEBERT, 1994, p. 30 e 31).

\subsubsection{Cristãos, igreja e missão como um conjunto indefinido intrínseco}

A definição de cristão se dá em termos de práticas e/ou crenças. A membresia é baseada em degraus na estrutura e a conversão raramente é um evento decisivo, pois é indefinido quando a pessoa se torna cristã. Nessa estrutura as pessoas podem participar de outras religiões (sincretismo), com isso, há pouca ênfase no evangelismo (HIEBERT, 1994). Os dogmas e práticas são assimilados em níveis de aceitação; não há importância para a maturidade do cristão quanto à participação na vida da igreja; não é esperado conversões, mas um crescimento no entendimento da fé cristã; esse modelo é perigoso pois tende a levar a igreja ao orgulho de louvar a si mesma ou de relativizar questões teológicas fundamentais (HIEBERT, 1994, p. 32 e 33). Outra questão é a ênfase no ecumenismo. É menos provável afirmar Cristo como único Senhor e Salvador. Não há ênfase na proclamação do evangelho, apologética fraca. Tende a levar ao relativismo ou niilismo. (HIEBERT, 1994, p. 34). 


\subsubsection{Conjunto Centrado}

Conjunto centrado é um agrupamento de objetos baseado em como se relacionam com outras coisas, não naquilo que são em si mesmas. É criado quando um centro ou ponto de referência se relaciona com os objetos. Os objetos se movimentam dentro de um campo em direção ao centro ou referência - característica de membresia. Quando os objetos estão se movimentando na direção oposta, são chamados de não-membros (HIEBERT, 1994, p. 35 e 36).

Há divisões claras separando os que estão relacionadas com o centro (dentro) e as que não estão relacionadas (fora). A maior ênfase está no centro e nos relacionamentos e não na manutenção da categoria. Todos os membros compartilham plenamente as funções do grupo. Relacionamentos estão em constante mudança, pois depende da proximidade ou não ao centro de referência. Pessoas podem se opor ao centro e retornar quando quiser (HIEBERT, 1994, p. 36).

Em termos bíblicos, podemos afirmar que a cosmovisão dos profetas e de Cristo tinha características extrínsecas e bem formadas, diferente dos gregos que entendiam Deus (ou deuses) de maneira intrínseca. Os israelitas tinham um entendimento relacional de Deus, podendo ser evidenciados nas alianças, pactos e como o povo se portava em comunidade. Jesus afirma que podemos conhecer a Deus, e que ele habita conosco e estará em nós (Jo 14.17). Paulo, em suas epístolas, deixa claro que nossa reconciliação com Deus se dá por meio de Cristo, onde o relacionamento é primordial e a lei é secundária. O Novo Testamento é melhor compreendido dentro da cosmovisão do conjunto centrado e relacional da cultura hebraica do que a cosmovisão intrínseca e estrutural dos gregos (HIEBERT, 1994, p. 37).

\subsubsection{Cristãos como conjunto centrado}

Conjunto centrado possui em sua categoria um centro de referência. O cristão, por sua vez, é definido como seguidor de um centro de referência, Jesus Cristo, e fazem dele o centro ou o senhor de suas vidas. A separação se dá entre os que seguem a Cristo e os que não o seguem. A ênfase evangelística seria em exortar as pessoas a seguirem a Cristo. Quanto a variação dos cristãos, se dá pelo grau de maturidade, onde todos são chamados a crescer até a plenitude de Cristo. A conversão significa reconciliação. As pessoas podem chegar ao conhecimento de Cristo de diversas maneiras: Salvador, Grande Deus, Grande Médico, Grande Libertador etc. (HIEBERT, 1994, p. 37-38). A natureza da conversão é de acordo com o 
contexto: pessoas que nascem em ambiente cristão precisam conhecer o senhorio de Cristo, pessoas que estão em rebelião e perdidas precisam conhecer Cristo como Salvador (HIEBERT, 1994, p. 39). Santificação não é algo estático, mas a justificação é dinâmica e contínua através de toda a vida. A maneira de trazer as pessoas para Cristo se dá pelo discipulado — cada decisão leva a pessoa em direção a Cristo ou fora dele. A abordagem de conjuntos centralizados evita oferecer uma "graça barata", que facilmente permite as pessoas se tornarem cristãs, ou "graça custosa" que preserva a pureza da igreja, mas impede as pessoas de entrarem no reino" (HIEBERT, 1994, p. 39).

O modelo centrado permite a igreja ser cristocêntrica, onde a membresia se baseia no relacionamento com Cristo e a comunhão seria o foco central da vida da igreja. A igreja é vista como família, focada em relacionamento e que desperta o sacerdócio dos crentes nos usos de seus dons (HIEBERT, 1994, p. 40). O discipulado é essencial para a conversão; a teologia se torna pública e não para alguns. Se por um lado o secularismo é possível nos conjuntos delineados, a idolatria é o maior mal dos conjuntos centrados. Acontece quando as pessoas colocam qualquer coisa no lugar de Deus. O entendimento de liderança nesse modelo é de uma equipe que promove a possibilidade de crescer em maturidade e não na visão de gurus espirituais (HIEBERT, 1994, p. 40-42).

\subsubsection{Conjuntos extrínsecos indefinidos}

Culturas que vivem uma cosmovisão panteísta poderia se encaixar nessa categoria. Nas sociedades totêmicas, ou na religião indiana as divisas humanas são indefinidas em relação às demais criaturas e há uma compressão de que animais, plantas e a natureza juntamente com o ser humano são frutos de uma força de vida (HIEBERT, 1994, p. 44). Em uma visão moderna, pode-se afirmar que o processo evolutivo darwinista é um exemplo - "toda a vida é vista como evoluindo em direções diferentes" (HIEBERT, 1994, p. 44).

\subsubsection{Cristãos como um conjunto extrínseco indefinido}

Primeiramente, não poderia haver parâmetros para o relacionamento com Cristo. "Para alguns ele é Senhor, e para outros, um tipo de guru, apontando-lhes o caminho. Outros o teriam como um grande filósofo [...] e para outros ainda, ele seria um homem bom a ser imitado" (HIEBERT, 1994, p. 45). Em segundo lugar, não haveria distinção entre cristão e não-cristão. 
Em terceiro, conversão uma série de diversos tipos de mudança, ou ainda, pode-se fazer de Cristo senhor de algumas áreas da vida e de outras não. Não existe ponto de conversão, pois é indefinido (HIEBERT, 1994, p. 45).

As mesmas características citadas acima se aplicam à igreja. A igreja é composta de uma pluralidade de pessoas em algum grau de relacionamento com Cristo. Não há divisas claras para fazer parte da comunidade, todos são bem vindos; conversão seria uma séria de decisões e mudanças de rota em direção a Cristo (HIEBERT, 1994, p. 46). A ação missionária batizaria de imediato os novos convertidos, a unicidade de Cristo como único caminho da salvação não tem relevância e haveria pouca importância para a evangelização e conversão. "Ao contrário, a ênfase estaria em ajudar cada pessoa a descobrir o caminho que melhor leva a Deus e uma fé que a satisfaz" (HIEBERT, 1994, p. 46).

\section{FUNÇÕES DAS COSMOVISÕES}

Hiebert propõe um diálogo coerente entre o ponto de vista filosófico, teológico e acrescenta os pressupostos antropológicos para compreender a função das cosmovisões e sua relevância na prática e vida e cristã.

Primeiramente ele recorre ao pensamento diacrônico utilizando o conceito de Brian Walsh para justificar que as cosmovisões servem a várias funções sociais e culturais importantes como estruturas coerentes que respondem às grandes perguntas existenciais: "onde estamos?”, “quem somos?”, “para onde vamos?” (WALSH E MIDDLETON, 2010, p. 30; KELLER, 2014, p. 41; HIEBERT, 2016, p. 34). Na visão antropológica as cosmovisões "surgem de nossa interação com o mundo, tanto individual quanto coletivamente" (HIEBERT, 2016, p. 35). Nossas cosmovisões possibilitam que nossas crenças e explicações façam sentido de forma óbvia e desapercebida de análise. "As cosmovisões fornecem modelos [...] da realidade que estrutura nossa percepção de realidade, mas os utilizamos como mapas para viver" (HIEBERT, 2016, p. 35).

Em segundo lugar, possuímos emoções. Por isso, "nossa cosmovisão fortalece nossas crenças fundamentais com reforços emocionais para que elas não sejam facilmente destruídas" (HIEBERT, 2016, p.35). A fé e a imaginação pautadas em uma cosmovisão nos dá segurança emocional. A fé é imaginação na medida em que compõe uma imagem sentida de um ambiente último. Criamos imagens a partir de nossas experiências de relacionamento nos contextos pactuais de nossa vida. Participamos, formamos e transformamos nossos relacionamentos 
pactuais em reciprocidade como o pano de fundo transcendente de sentido e poder em relação ao qual damos sentido à nossa vida; conforme esse relacionamento recíproco entre ambiente último imaginado e a vida diária sugere, a vida imaginadora da fé é dinâmica e muda constantemente (FOWLER, 1992, p. 40).

Em terceiro lugar, a cosmovisão dá uma noção de segurança de que o mundo que vivemos, faz sentido. Somos racionais e, por natureza, categorizamos, criamos mapas mentais para organizar e buscar uma visão de realidade unificada (HIEBERT, 2016, p. 35). Nesse aspecto, a visão diacrônica nos ajuda a mapear a realidade e ver de forma telescópica a cosmovisão em um sentido racional e categórico. Tudo isso é compartilhado na vida em sociedade, numa integração cultural.

Outro aspecto sobre a função de cosmovisões, é que elas permitem que avaliemos as experiências e ações em termos de justiça, pecado, transgressão, obediência/desobediência (HIEBERT, p. 35). Nossas relações de confiança e lealdade aos nossos companheiros em comunidade são aprofundadas e sancionadas pelas nossas confianças e lealdades partilhadas para com centros transcendentes de valor e poder (FOWLER, 1992, p. 40). A estrutura pactual de nossas relações humanas significativas frequentemente se torna visível tanto por nossas traições e faltas de "boa fé" quanto pelas ocasiões em que somos mutuamente leais e fieis (FOWLER, 1992, p. 40). Esse diálogo entre Hiebert e Fowler reforça que as cosmovisões nos ajudam a viver normas culturais impostas através de um centro transcendente de valor e poder. Cumprimos aquilo que faz sentido, mesmo que a cosmovisão como centro de valor e poder estejam erradas, do ponto das Escrituras.

Por fim, Hiebert destaca que as cosmovisões nos dão segurança e confiança psicológica de que o mundo é o que é. "A cosmovisão das pessoas entra em crise quando há um abismo entre sua cosmovisão e sua experiência de realidade" (HIEBERT, 2016, p. 36). Nesse sentido, o abismo promove o confronto do indivíduo com seus próprios dilemas, "as supostas crises são um trampolim, impulsos para a maturidade e instrumentos de aprendizagem" (FOWLER, 1992, p. 166). A cosmovisão bíblica, de fato, dá segurança emocional, psicológica e promove em um processo de santificação a maturidade. Sobre a relevância da cosmovisão bíblica, Walsh e Middleton (2010, p. 36) afirmam que se "nossa cosmovisão é informada, corrigida e moldada pelas Escrituras sob o direcionamento do Espírito, receberemos orientação para nosso modo de vida". Pelas Escrituras e através do Espírito Santo somos desafiados a viver uma cosmovisão bíblica que além de nos redimir nos dá a possibilidade de transformar cosmovisões doentias que levam a morte. 


\section{CONSIDERAÇÕES FINAIS}

Podemos concluir que o estudo do conceito "cosmovisão" é complexo e é definido de acordo com o espírito da época. Podemos utilizar os conceitos filosóficos, teológicos, linguísticos e antropológicos para interpretar o conceito, mas não podemos deixar de responder: por que estudar cosmovisões?

Primeiramente, estudar cosmovisão faz compreender de qual história fazemos parte. Vivemos em uma encruzilhada e uma guerra de cosmovisões. O mundo ocidental é pautado numa cosmovisão humanista que destrona Deus da natureza e que coloca o homem no nível dos ratos - o humanismo destitui a peculiaridade e particularidade do homem como imago dei e coloca-o para ser analisado in vitro, como objeto de estudo dentro das categorias meramente racionais. Nossas igrejas e muitas das nossas práticas cristãs foram moldadas por essa cosmovisão que leva à morte. A cosmovisão bíblica é a resposta que nos leva a entender que fazemos parte da missão de Deus na grande narrativa bíblica.

Em segundo lugar, o estudo de cosmovisão possibilita uma melhor compreensão do campo missionário seja ele na nossa casa, igreja, bairro ou nação. Infelizmente nossa missão está apenas pautada na mudança de comportamento e transformação de crenças. A mudança de cosmovisão leva a um verdadeiro entendimento do que significa Deus, criação, homem, cultura, economia e outras esferas. Levando em conta as cosmovisões e como elas funcionam, pode ser uma excelente oportunidade para realizar pontes com o evangelho, transformando assim as cosmovisões à luz das Escrituras.

Por último, em Romanos 12.1-3, Paulo exorta que devemos decidir, de forma racional, oferecer nosso corpo como sacrifício agradável a Deus na maneira como vivemos. Como cristãos, somos transformados pela renovação da mente. Quem faz isso é o Espírito Santo. Essa renovação nos dá a chance de avaliar o presente momento com a ética e cosmovisão do mundo por vir. Keener $(2018$, p. 253) afirma que no contexto anterior ao capítulo 12 de Romanos, Paulo mostrou como a mente de Deus se revela no plano histórico, fornecendo uma base sobre como devemos viver e adorá-lo. O que significa viver uma mente renovada, ou uma cosmovisão nos moldes de Deus? A resposta está na busca relacional com ele. Desta forma, podemos viver a plena confiança e renovação à semelhança de Deus para viver no mundo. A cosmovisão bíblica transforma outras cosmovisões, pois é a cosmovisão da vida humana verdadeira, da visão de mundo verdadeira, da verdadeira doação em favor dos outros, assim como Deus o fez. 
Cosmovisão são pressupostos cognitivos, afetivos e avaliadores que nos faz compreender que Deus está conduzindo a história de toda a criação no palco do mundo. E que podemos participar de forma relevante e transformadora essa história.

\section{REFERÊNCIAS}

AZEVEDO, Antonio Carlos do Amaral. Dicionário histórico das religiões. Rio de Janeiro: Nova Fronteira, 2002.

BAUMAN, Zygmunt. Modernidade líquida. Rio de Janeiro: Zahar, 2001.

BÍBliA. A Bíblia Sagrada: Antigo e Novo Testamento. Tradução de João Ferreira de Almeida. Edição rev. e atualizada no Brasil. Brasília: Sociedade Bíblia do Brasil, 1969.

DOUGLAS, Mary. Pureza e perigo. São Paulo: Perspectiva, 1976.

FOWLER, James W. Estágios da fé. São Leopoldo: Sinodal, 1992.

GEERTZ, Clifford, A vida entre os antros e outros ensaios. Petrópolis: Vozes, 2015.

GOHEEN, Michel W.; BARTHOLOMEW, Craig G. Introdução à cosmovisão cristã. São Paulo: Vida Nova, 2016.

GOMBRICH, Ernst H. A História da arte. Rio de Janeiro: LTC, 1999.

GONZÁLEZ, Justo L. Cultura e evangelho: o lugar da cultura nos planos de Deus. São Paulo: Hagnos, 2011.

HIEBERT, Paul. Anthropological reflections on missiological issues. Grand Rapids: Baker Academic, 1994.

Transformando cosmovisões: uma análise antropológica de como as pessoas mudam. São Paulo: Vida Nova, 2016.

KELLER, Timothy. Igreja centrada: desenvolvendo em sua cidade um ministério equilibrado e centrado no evangelho. São Paulo: Vida Nova, 2014.

MALINOWSKI, Bronislaw. Crime e costume na sociedade selvagem. Petrópolis: Vozes, 2015.

MARCONDES, Danilo. Iniciação à história da filosofia: dos pré-socráticos a Wittgenstein. Rio de Janeiro: Zahar, 2008. E-book.

MARTELOTTA, Mário Eduardo. Manual de Linguística. São Paulo: Contexto, 2012.

NAUGLE, David. Filosofia: um guia para estudantes. Brasília: Monergismo, 2014. E-book.

Cosmovisão: a história de um conceito. Brasília: Monergismo, 2017. E-book.

PEARCEY, Nancy. Verdade absoluta: libertando o cristianismo de seu cativeiro cultural. Rio de Janeiro: CPAD, 2006.

ROOKMAKER, Hans R. Filosofia e estética. Brasília: Monergismo, 2018. E-book. 
SIEMENS, Udo. Quem somos? A saga menonita: rompendo a barreira cultural. Curitiba: Esperança, 2010.

SIRE, James W. Dando nome ao elefante. Brasília: Monergismo, 2012. E-book.

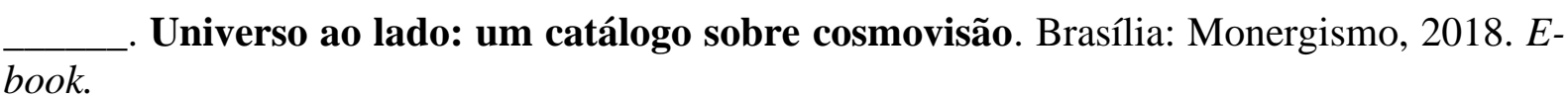

WALSH, Brian J.; MIDDLETON, J. Richard. A visão transformadora. São Paulo: Cultura Cristã, 2010. 